76 EFFECTS OF CONCRETE BIT WEAR ON DRILL HANDLE VIBRATION, DRILLING PRODUCTIVITY AND CHANGES IN BIT TIP GEOMETRY

${ }^{1}$ David Rempel, ${ }^{1}$ Andrea Antonucci, ${ }^{2}$ Lucia Botti, ${ }^{2}$ Cristina Mora, ${ }^{1}$ Bernard Martin, ${ }^{1}$ Alan Barr. 'Department of Bioengineering, University of California, Berkeley, USA; ${ }^{2}$ Department of Industrial Engineering, University of Bologna, Italy

\subsection{6/oemed-2018-ICOHabstracts. 1486}

Introduction The use of hammer drills for concrete drilling exposes construction workers to high levels of hand vibration that may lead to hand arm vibration syndrome and other musculoskeletal disorders. The aim of this study was to investigate the effects of concrete bit wear on drill handle vibration, productivity, and change in bit shape.

Methods A laboratory test bench system was used to automatically advance an active $8.3 \mathrm{~kg}$ hammer drill with a $1.9 \mathrm{~cm}$ diameter carbide-tipped bit into aged concrete block under feed force control to a depth of $7.5 \mathrm{~cm}$ while drill handle vibration (ISO 5349 and 28927) and penetration rate $(\mathrm{mm} / \mathrm{s}$ ) were measured. Bits were worn to 4 levels by consecutively drilling holes to cumulative depths of $0,1900,5700$ and $7600 \mathrm{~cm}$. Image analysis methods quantified 13 geometric parameters of the carbide tip. Changes in the geometric parameters were compared to changes in penetration rate.

Result $\mathrm{Z}$-axis handle vibration increased significantly $(\mathrm{p}<0.05)$ from 4.8 to $5.1 \mathrm{~m} / \mathrm{s}^{2}$ (ISO weighted) and from 42.7 to 47.6 $\mathrm{m} / \mathrm{s}^{2}$ (unweighted) when comparing a new bit to a bit worn to $1900 \mathrm{~cm}$ of cumulative drilling depth, but did not increase further with more wear. Drilling time increased by $58 \%$ for the worn $(5700 \mathrm{~cm})$ bit compared to a new bit. Changes in bit shape highly correlated to reduced productivity were increased fluke slope, increased shoulder rounding, and decreased tip width.

Discussion Carbide-tipped bit wear was associated with a small increase in ISO weighted and unweighted z-axis handle vibration and a large decrease in drilling productivity. To reduce drill-handle vibration levels and exposure time to hand vibration, construction contractors should implement a bit replacement program guided by bit wear. Other controls, such as exposure time per day, may also be necessary to adequately protect workers from hazardous levels of hand vibration.

\section{A NOVEL MEASUREMENT TECHNIQUE FOR THE ASSESSMENT OF INDUSTRIAL ULTRASONIC NOISE}

${ }^{1} \mathrm{C}$ Ullisch-Nelken*, ${ }^{2} \mathrm{R}$ Schöneweiß, ${ }^{2} \mathrm{C}$ Kling, ${ }^{1} \mathrm{~A}$ Wolff. ${ }^{1}$ Insitute for Occupational Safety and Health, Sankt Augustin, Germany; ${ }^{2}$ Physikalisch-Technische Bundesanstalt, Braunschweig, Germany

\subsection{6/oemed-2018-ICOHabstracts. 1487}

Introduction Although the possible negative health effects of exposure to high energetic ultrasonic noise were discussed since the adoption of the technology in the 1940s, no major research was conducted on this topic since the late 20th century and it only regained focus approximately 10 years ago. Nevertheless, guideline values and limits have been established for the exposure to ultrasonic noise in several countries. The Ears II project was brought to life under the umbrella of the EU's EMPIR, to investigate the human perception of nonaudible sound and its possible effects on human health. In this context the Institute for Occupational Safety and Health and the National Metrology Institute of Germany developed a measurement technique for assessing industrial ultrasonic noise.

Methods Existing measurement techniques for audible sound were evaluated for their applicability to measuring ultrasound. Through evaluation of existing data a reference workplace was developed for laboratory measurements. These comprised simulated practical measurements and high spatial resolution scans of the sound field of an ultrasonic welding machine. Finally, a method was developed and tested in field measurements.

Results The existing standards for assessment of the exposure to noise negate the applicability to ultrasonic noise. The same is true for the standards covering technical requirements for sound level metres. A novel technique was successfully developed and field measurements were carried out.

Conclusion The existing standards are mostly insufficient for the assessment of the exposure to ultrasonic noise. Either applicability to ultrasound is ruled out a priori or the methods or technical specifications are insufficient for the measurement of ultrasound, because the frequency range of interest is not covered, for example.

Based on an existing guideline a novel method was developed, which will, if necessary, be adapted to practical needs after examination of its practical applicability by evaluation of the field tests.

\section{RETURN TO WORK AMONG SELF-EMPLOYED CANCER SURVIVORS: A EUROPEAN COMPARATIVE STUDY}

${ }^{1} \mathrm{~S}$ Torp*, ${ }^{2} \mathrm{~A}$ Paraponaris, ${ }^{3} \mathrm{EV}$ Hoof, ${ }^{4} \mathrm{ML}$ Lindbohm, ${ }^{5} \mathrm{~S} J$ Tamminga, ${ }^{2} \mathrm{C}$ Alleaume, ${ }^{6}$ AT Gavin, ${ }^{3} \mathrm{NV}$ Campenhout, ${ }^{5} \mathrm{AGEM}$ de Boer, ${ }^{7} \mathrm{~L}$ Sharp. ${ }^{1}$ University College of Southeast Norway, Tonsberg, Norway; ${ }^{2}$ Aix-Marseille University, Marseille, France; ${ }^{3}$ Free University of Brussels, Brussels, Belgium; ${ }^{4}$ Finnish Institute of Occupational Health, Helsinki, Finland; ${ }^{5}$ Coronel Institute of Occupational Health, Amsterdam, the Netherlands; ${ }^{6}$ Ireland Cancer Registry, Queen's University Belfast, Belfast, UK; ${ }^{7}$ Newcastle University, Newcastle-uponTyne, UK

\subsection{6/oemed-2018-ICOHabstracts.1488}

Introduction Studies on cancer survivors' (CS) return to work (RTW) after cancer have mostly focused on salaried workers. RTW among self-employed CS has almost not been focused although there are big differences in these two groups' working conditions and social welfare provisions. The aim of this study is therefore to bring together data from multiple European countries to:

- describe RTW-related outcomes after cancer in selfemployed people;

- compare these outcomes for the self-employed with those for salaried workers; and

- describe RTW-related outcomes after cancer for selfemployed people across countries.

Methods Eleven cross-sectional studies from seven countries were included. All studies had survey data on work-outcomes in self-employed and salaried CS who were employed at time of diagnosis ( $n=22-261$ self-employed/101-1627 salaried). The studies included different cancers and assessed different outcomes at different times post-diagnosis.

Results Fewer self-employed CS took time off work due to cancer compared to salaried survivors. More self-employed than salaried worked post-diagnosis in almost all countries. Among those working at the time of survey, self-employed survivors had made a larger reduction in working hours compared to pre-diagnosis, but they still worked more hours per 